\title{
ENVIRONMENTAL ASPECTS OF TRANSPORT IN THE CONTEXT OF DEVELOPMENT OF INLAND NAVIGATION
}

\author{
ANDREA GALIERIKOVÁ, JARMILA SOSEDOVÁ
}

Department of Water Transport, The Faculty of Operation and Economics of Transport and Communications, University of Žilina, Univerzitná 8215/1, 01026 Žilina, Slovak Republic; e-mail: andrea.galierikova@fpedas.uniza.sk, jarmila.sosedova@fpedas.uniza.sk

\begin{abstract}
Galieriková A., Sosedová J.: Environmental aspects of transport in the context of development of inland navigation. Ekológia (Bratislava), Vol. 35, No. 3, p. 279-288, 2016.

Transport has an immense impact on the environment. The largest share of environmental pollution is caused by road transport. The atmosphere is threatened by fuel combustion of engines of road vehicles, thereby leading to the global warming of Earth. In addition to having an adverse impact on the environment, such as greenhouse gas emissions and carbon dioxide emissions, road transport also leads to external effects such as noise pollution, vibration, congestion and traffic accidents. The volume of transport in the world, notably on the roads, is increasing day by day. We should take the necessary steps to move to more environmentally-friendly modes of transportation, such as rail and inland navigation. Rail transportation is currently the largest competitor of road transport. If the waterways infrastructure is improved, there would be a decrease in the traffic flow of motorways and thus, we can move to a more environmentally-friendly transportation.
\end{abstract}

Key words: modal split, inland waterways, petroleum fuel consumption, greenhouse gas emissions, energy consumption per tonne.

\section{Introduction}

The modes of transportation can be categorised into three basic groups on the basis of the kind of surface they travel on, namely land (road and rail), water (shipping - hinterland or maritime) and air. These modes are described by a set of characteristics as technical, operational and commercial. Each mode of transport has its own advantages and disadvantages relating to price, speed, safety, security and reliability. Differences in price, capacity and services push each mode to behave economically. Figure 1 presents the spectrum of transportation characteristics of each transportation mode.

On the left side of the spectrum is water transport, being the lowest cost carrier and also the slowest mode. On the right side, there is air transport that offers fast transportation, but very high prices. In the middle are road and rail transport (as intermodal). The basic rule is that shipments with higher value and lower weight, and perishable goods should be transported by road and air transportation, and goods with lower values and bigger weight should be transported by rail and water transportation. 


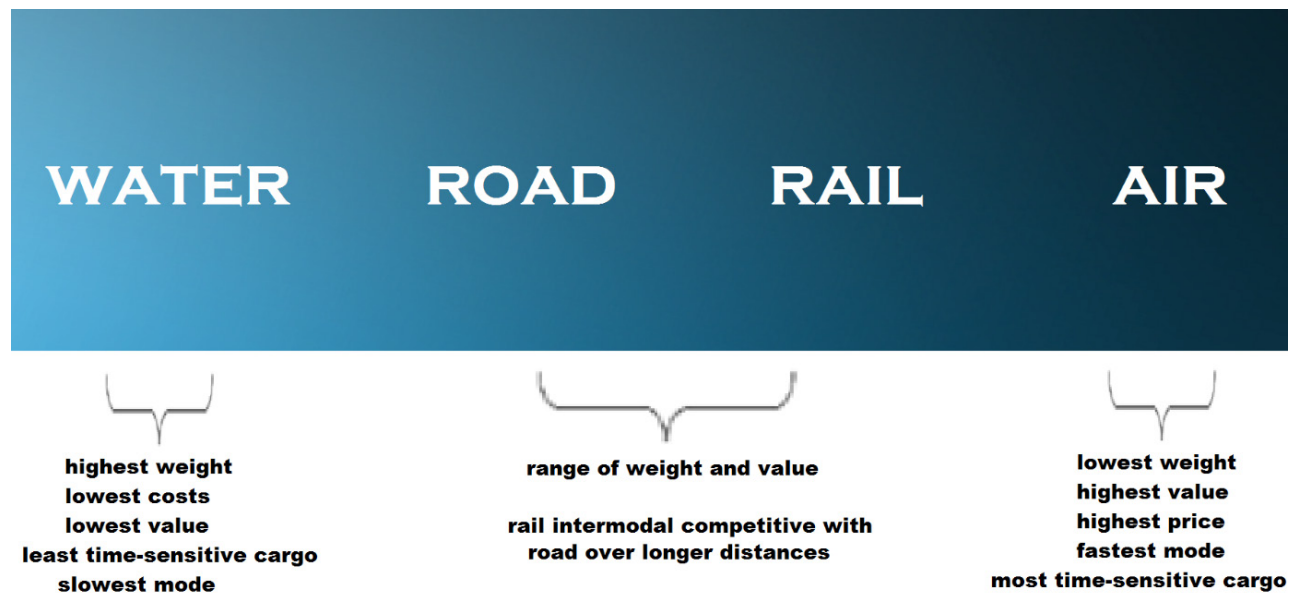

Fig. 1. Spectrum of transportation characteristics (compiled by the author)

Modal choice depends on several factors. The selection of these characteristics depends on specific conditions such as location of production, number and location of suppliers, etc.; therefore there cannot be an exact formula to decide the mode of transport. Several basic areas are common to each mode. The main factors related to the nature of the freight, ways and especially costs are described in the Table 1.

T a b le 1. Factors influence modal choice (Eurostat, 2016).

\begin{tabular}{|l|l|l|l|}
\hline Modal factors & Commodity factors & $\begin{array}{l}\text { Shipper and receiver } \\
\text { characteristics }\end{array}$ & \multirow{2}{*}{ Additional factors } \\
\hline Capacity & Size & Handling costs & Length of haul \\
\hline Reliability & Package characteristics & Transportation charges & Shipment frequency \\
\hline Equipment & Shipment value & Service costs & \multirow{2}{*}{ Environmental } \\
\cline { 1 - 2 } Trip time & Shipment density & Inventory costs & \multirow{2}{*}{} \\
\cline { 1 - 2 } Customer service & Shipment shelf life & Loss and damage costs & \multicolumn{2}{|l}{} \\
\cline { 1 - 2 } Handling quality & \multicolumn{2}{|l}{} &
\end{tabular}

Price as the main factor can influence the decision of a suitable mode of transport. The increase of prices of the fuel can encourage companies to go for less fuel consuming transportation, which can also be cheaper. Flexibility is the other element which works in favour of road transport as it can do a door-to-door service, while the other modes of transport cannot provide this facility. The capacity of each mode of transport is quite different. In terms of capacity, inland waterway transport dramatically leads as compared to the other modes of transport. The typical capacity of an inland barge is 15 times greater than one railway wagon and 70 times greater than one semi-trailer truck unit, as it shows Fig. 2 (Brogan et al., 2013). 


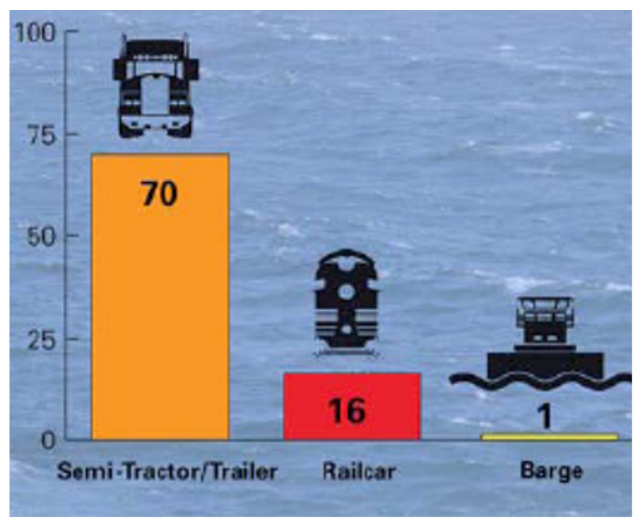

Fig. 2. Comparison of modal capacity (Brogan et al., 2013).

\section{Material and methods}

Modal split means the share of different modes of transport that are used in a certain territory during a particular period of time, and it is generally measured in tonne-kilometres. Modal split in the European Union is different. These shares are examined by the EU institutions the European Commission and the European Environmental Agency. Table 2 shows the level of modal split of inland freight transport in each country of the EU.

T a b l e 2. Modal split in the EU in billion tonne-kilometres (Eurostat, 2016).

\begin{tabular}{|l|c|c|c|c|c|c|c|}
\hline Year & Road & Rail & Waterways & Pipelines & Sea & Air & Total \\
\hline $\mathbf{2 0 0 3}$ & 1608 & 394 & 124 & 132 & 1119 & 2 & 3378 \\
\hline $\mathbf{2 0 0 4}$ & 1751 & 419 & 137 & 133 & 1159 & 2 & 3601 \\
\hline $\mathbf{2 0 0 5}$ & 1795 & 416 & 139 & 138 & 1198 & 2 & 3687 \\
\hline $\mathbf{2 0 0 6}$ & 1858 & 438 & 139 & 137 & 1224 & 2 & 3798 \\
\hline $\mathbf{2 0 0 7}$ & 1925 & 452 & 145 & 128 & 1190 & 2 & 3843 \\
\hline $\mathbf{2 0 0 8}$ & 1891 & 443 & 146 & 125 & 1164 & 2 & 3771 \\
\hline $\mathbf{2 0 0 9}$ & 1700 & 364 & 131 & 122 & 1062 & 2 & 3880 \\
\hline $\mathbf{2 0 1 0}$ & 1755 & 394 & 156 & 121 & 1118 & 2 & 3546 \\
\hline $\mathbf{2 0 1 1}$ & 1744 & 422 & 142 & 118 & 1133 & 2 & 3562 \\
\hline $\mathbf{2 0 1 2}$ & 1693 & 407 & 150 & 115 & 1113 & 2 & 3480 \\
\hline $\mathbf{2 0 1 3}$ & 1791 & 407 & 153 & 112 & 1089 & 2 & 3481 \\
\hline
\end{tabular}

The volume of shipments transported to and from the EU is constantly increasing. Figure 3 shows that in 2013, the biggest share took road transport (49.4\%) of total inland freight transport (based on tonne-kilometres). The share of rail transport increased in comparison to the previous years, and in 2013 , it reached $11.7 \%$. The share of water transport was $35.6 \%$ in 2013.

Table 3 displays the modal split in 2012 in the five main world economies. The table also includes data on domestic sea shipping and pipelines. Two main oil producers have meaningful pipelines shares. In terms of other inland modes, the dominant countries are USA, Russia and China. Inland navigation has a lower share of transport except for China (which represents $16 \%$ of the total tonne-kilometres.) 


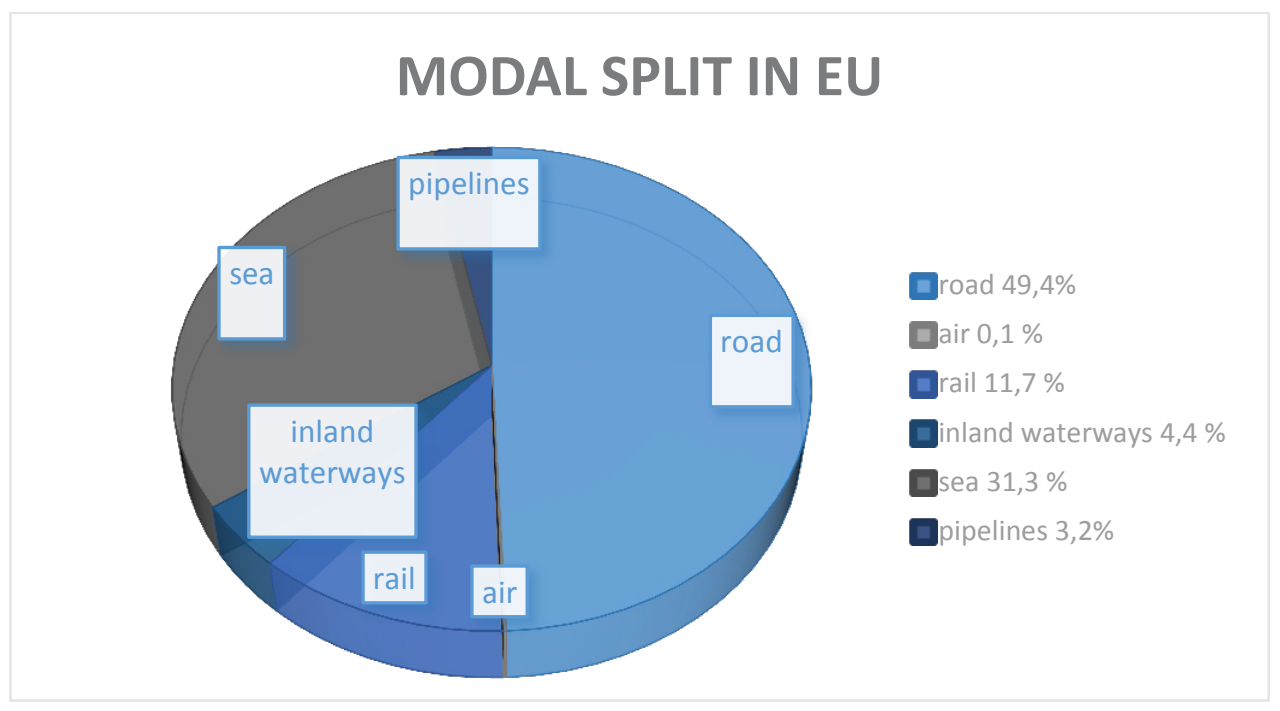

Fig. 3. Modal split in 2013 (Eurostat, 2016).

T a b le 3. Modal split in the world in 2012 (Eurostat, 2016).

\begin{tabular}{|l|c|c|c|c|c|}
\hline Transport (bil. tonne-km) & EU - 28 & USA & Japan & China & Russia \\
\hline Road & 1692.6 & 2038.9 & 210 & 5953.5 & 249 \\
\hline Rail & 407.2 & 2649.2 & 20.5 & 2918.7 & 2222 \\
\hline Inland waterways & 150 & 464.7 & - & 2829.6 & 61 \\
\hline Oil pipeline & 114.8 & 968.6 & - & 317.7 & 2453 \\
\hline Sea (domestic/intra-EU 28) & 1401 & 263.1 & 177.6 & 5341.2 & 45 \\
\hline
\end{tabular}

Water connections in the EU member states

The research of the European modal split by countries shows that the Netherlands has the biggest share of inland waterways. This is can be attributed to good canal infrastructures and connectivity on the Rhine. The strategic location of the Netherlands - on the Rhine Delta, and good connectivity with the European network of inland waterways makes Dutch a significant freight carrier in Europe. In 2013, the proportion of freight transported by Dutch waterways was comparable to the volume of freight transported by road (47.1\%). In Bulgaria and Romania, the share of water transport is $30 \%$ of the total freight transportation, which is due a large volume of traffic on the Danube. Germany and Belgium, as neighbours of the Netherlands, also have an important share of the European inland waterways ( $14 \%$ and $12 \%$, respectively, Eurostat).

$\mathrm{T} \mathrm{a} \mathrm{b} \mathrm{l} \mathrm{e} \mathrm{4.} \mathrm{The} \mathrm{EU} \mathrm{countries} \mathrm{and} \mathrm{access} \mathrm{to} \mathrm{IW} \mathrm{network} \mathrm{(US} \mathrm{Bureau} \mathrm{of} \mathrm{Transport} \mathrm{Statistics).}$

\begin{tabular}{|l|l|}
\hline & Countries \\
\hline Access & $\begin{array}{l}\text { Belgium, Bulgaria, Austria, Czech Republic, France, Germany, Hungary, Luxembourg, Nether- } \\
\text { lands, Romania and Slovakia }\end{array}$ \\
\hline No access & $\begin{array}{l}\text { Cyprus, Denmark, Estonia, Finland, Greece, Iceland, Italy, Norway, Ireland, Latvia, Lithuania, } \\
\text { Malta, Poland, Portugal, Turkey, Slovenia, Spain, Sweden and United Kingdom }\end{array}$ \\
\hline
\end{tabular}


The Danube river, with its connectivity to the Rhine by Main-Donau-Kanal, is particularly important for its navigable sections. Countries such as Germany, Austria, Slovakia, Hungary, Romania and Bulgaria use it for commercial navigation. These two main European rivers create the European inland waterway network and connect the North Sea and the Black Sea. Table 4 shows the classification of European countries on the basis of their access to the inland waterway (IW) network (US Bureau of Transport Statistics).

\section{Results}

Transport, especially road transport, adversely affects the environment and all living organisms. Secondary effects such as road congestions, accidents and related loss of health and life, noise pollution and vibration are not included in the total costs of transportation. Presently, the external (secondary) costs from road transport denote more than $30 \%$ of automobile costs.

\section{Transportation and energy}

The use of different modes of transport translates into consuming different volumes of energy per unit of cargo movement. With regard to energy consumption per tonne of freight, inland water transport is considered as one of the most effective mode of transport. Using environmentally friendly vessels on inland waterways can ensure energy and cost savings. In the EU, there is a need to introduce uniform rules on using environmentally friendly vessels. Research has shown that enough water depth and length of inland vessels (about 1500 ton load on 95-110 m lengths) can reduce more energy consumption per loaded tonne than smaller units. Change in the structure of vessels means more energy-efficient cargo vessels that can decrease fuel consumption by circa 9\% (Rodrigue, 2013). Figure 4 shows a comparison of distances one tonne of freight transported by various modes of transport, using the same amount of energy (water transport includes inland, short sea and coastal navigation).

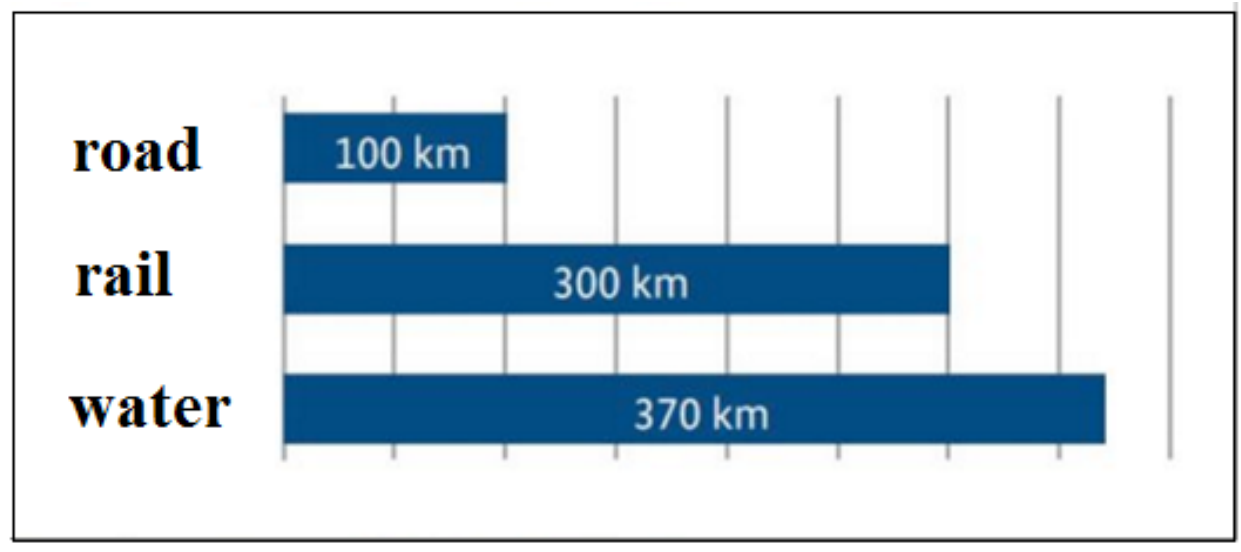

Fig. 4. Comparison of distance travelled for transporting one tonne of freight with same energy consumption (Federal W\&S Administration). 


\section{Transportation and emissions}

Freight transportation has obviously increased in recent years. This increase has not been proportional for all transport modes - some modes have increased their shares to the detriment of others. This has caused changes in the $\mathrm{CO}_{2}$ emissions and GHG emissions.

Different means of transport that carry goods have diverse characteristics in terms of energy intensity. Water and rail transport are much less energy consuming than road and air. Air transport is very energy intensive even though it represents only a small proportion of freight transport. It is clear that road transport is the most invasive mode in terms of emissions.

Is it possible to change the mode of transport from the ones with high fuel consumption (like road or air transport) to more fuel efficient modes (like rail and water transport), which will help in reducing the use of energy (principally petroleum-fuel) and emission of greenhouse gases? Freight transportation represents about $26 \%$ of all fuels based on petroleum (diesel, gasoline, etc.) that are consumed in the transport sector. More details about GHG emissions in EU are shown in the Table 5.

T a b l e 5. GHG emissions - EU 28 (mil. tonnes $\mathrm{CO}_{2}$ ) (Eurostat).

\begin{tabular}{|l|c|c|c|c|c|c|c|}
\hline \multirow{2}{*}{ Years } & Passengers & \multicolumn{5}{|c|}{ Freight } \\
\cline { 2 - 8 } & Civil aviation & Road & Rail & $\begin{array}{c}\text { Inland } \\
\text { waterways }\end{array}$ & Sea & $\begin{array}{c}\text { Other } \\
\text { transportation * }\end{array}$ & Total \\
\hline $\mathbf{1 9 9 0}$ & 84.1 & 722.4 & 13.5 & 22.9 & 110.2 & 9.6 & 962.6 \\
\hline $\mathbf{1 9 9 5}$ & 101.3 & 782.7 & 10.6 & 21.9 & 111.2 & 8.4 & 1036.2 \\
\hline $\mathbf{2 0 0 0}$ & 135.8 & 859.5 & 9.5 & 20.4 & 134.3 & 9.1 & 1168.6 \\
\hline $\mathbf{2 0 0 5}$ & 151.6 & 912.7 & 8.0 & 21.0 & 166.4 & 10.4 & 1270 \\
\hline $\mathbf{2 0 1 0}$ & 149.7 & 883.0 & 7.3 & 19.2 & 155.8 & 9.5 & 1224.5 \\
\hline $\mathbf{2 0 1 2}$ & 150.7 & 843.2 & 7.1 & 17.2 & 145.6 & 9.4 & 1173.3 \\
\hline
\end{tabular}

* Other: pipeline transportation, ground activities at airports and harbours and off-road activities

Petroleum fuel consumption is closely linked to greenhouse gas emissions. Figure 5 shows the share of petroleum fuel use by each means of transport. In 2012, the emissions from road transport presented $72 \%$ of the total GHG emissions. The emissions from inland waterways were $10 \%$ and from rail, only $1 \%$. (Eurostat).

Although carbon dioxide emissions are the most noted kind of pollution, it is not the only negative outcome of transport. A lot of these impacts (pollution, congestions, noise and vibrations) are not included in the final price of transportation. According to K. Eriksen, Senior research economist Institute of Transport Economics of Oslo, Norway: 'Transport activities are known to have substantial negative external effects. One of the reasons for trying to value these effects is that the cost to society of using a specific transport mode should be reflected in the price that is paid by the transport user and thus, form the basis for the transportation tax policy'. 


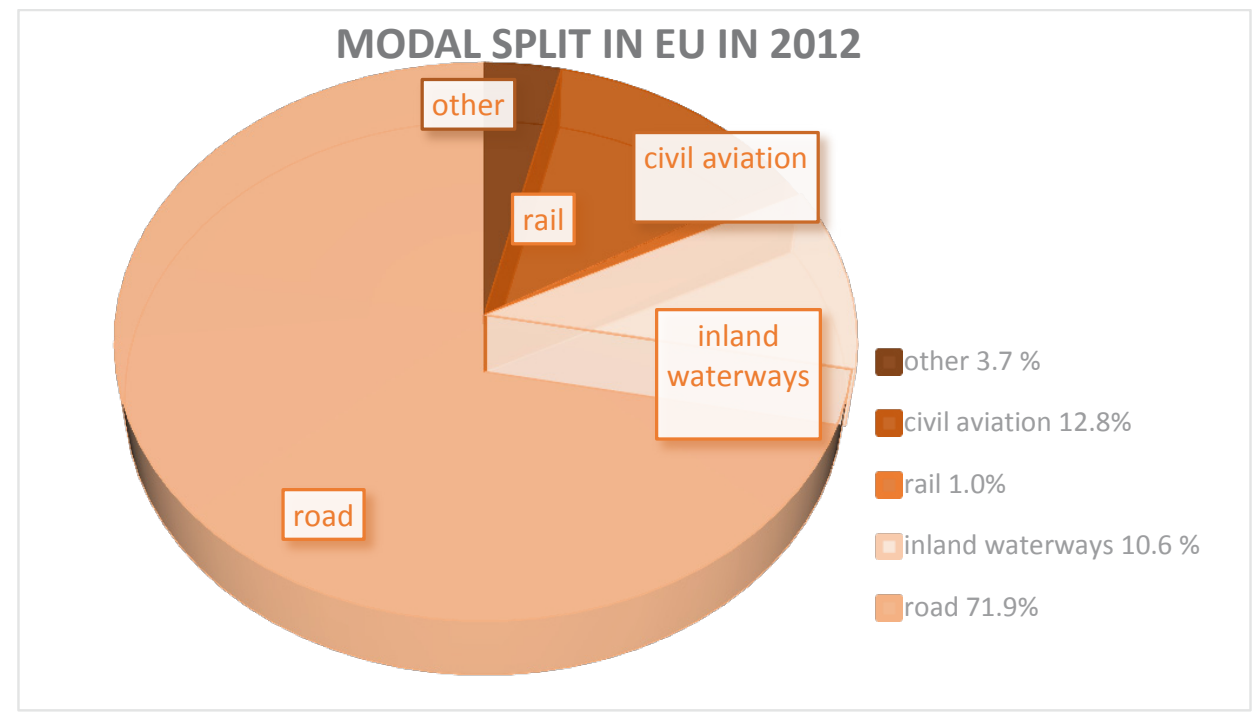

Fig. 5. Share of $\mathrm{CO}_{2}$ emissions in EU 28 in 2012 (Eurostat, 2016).

Hypothetically, to make the most polluting modes of transport more expensive can help to make the freight sector more environment-friendly. As quoted by Jourquin et al., 'One way to partly shift transport demand on trains and barges is to introduce a pricing/taxation policy which takes into account these external costs for the different modes.' (Fuchs, 2010).

In the future, there is an assumption to shift truck traffic to inland and coastal navigation and rail transportation. The reason is that because of greater efficiency of road transport, highways are overloaded and the transport time is often extended. The facilitation of highways could ensure a reduction in accidents and avoid negative environmental impacts such as harmful $\mathrm{CO}_{2}$ and GHG emissions.

\section{Truck to rail modal shifts}

Road transportation is characterised by providing door-to-door service with high reliability and speed, but higher costs, while rail transportation specialises in terminal to terminal service with lower speed and reliability. Historically, the main advantage of rail transportation over road has been the lower costs. With its very similar performance, rail is the main competitor of road transport. Intermodal ${ }^{1}$ transportation for greater distances (more than 500 kilometres) can provide attractive market for truck-to-rail modal shift. The intermodal rail service allows a shipper to move goods for long distances by rail (without paying for the driver of a truck) and also, without unpacking the boxes. Commodities that can be carried in containers are best suited to diversion from truck to rail. Other kinds of trucks as liquid

\footnotetext{
${ }^{1}$ Transportation involving more than one form of carrier, as truck and rail, or truck, ship, and rail.
} 
bulk tankers or flatbeds can be handled by rails that use roll-on/roll-off ${ }^{2}$ (Ro-Ro). The main advantages of Ro-Ro are:

- Shorter shipment distances.

- Each Ro-Ro rake carries 40 trucks and saves approximately 10 litres of diesel per km.

- Drivers have no reliability for their trucks that are moving on the train.

- Shorter travel time (Reis et al., 2013).

Of course, there are some types of commodities that cannot be transported by train. For example, time sensitive freight or commodities in smaller quantities have to be transported by truck because rail is not efficient enough. In the terms of corridors, there are many rail lines that have significant speed restrictions, so they cannot be competitive with truck for short or medium distances.

European commission has set the goal of shifting $30 \%$ of the road freight that is travelling more than 300 kilometres to rail or water transport by 2030 . To meet the target, it is necessary to invest in innovations in the infrastructure (by program Marco Polo 1 and also grants from private firms that are able to provide transportation solutions) (McKinnon, 2015).

\section{Truck to water}

Water transport can be used for cheaper movement of goods and generates less greenhouse gas emissions than other modes of transport. The interest in diverting transportation through truck or rail to coastal and waterway navigation has increased significantly. Short-sea, coastal and inland shipping can replace marine shipping - between two and more ports along a single coast, including a short sea move or manoeuvring through inland waterways. The types of water transportation mentioned above have provided a lot of freight transportation for a hundred years (for example, salvage, towing, etc.).

The main problem in using inland water transport is that the existing infrastructure is unable to handle large volume of short-sea traffic. Inland waterway transport in the EU is based on the Rhine and the Danube River. Other waterway systems are not maintained. The rivers don't have enough depth and also, do not have completed locks, dams, channels and clearance of bridges. So, the parameters do not allow commercial shipping. However, investments to improve inland navigation should guarantee that these problems are eliminated and the modal shift will be successful.

\section{Discussion}

In an effort to declarate the negative impacts of transportation, we performed an analysis of transport performance in recent years. The analysis showed that the most polluting transport mode is road transport. This argument is based on research of the quantity of $\mathrm{CO}_{2}$ and GHG emissions produced by each transportation mode in recent years.

The most of GHG emissions from transport are carbon dioxide emissions resulting from fuels in combustion engines. The largest producers of emissions are road vehicles, such as passenger cars, trucks and light duty trucks.

${ }^{2}$ Roll-on/roll-off: loaded trucks are directly carried by railway wagons to their destination. 
In 2013, GHG emissions from transport was about $27 \%$ of the total produced emissions, making it the second biggest contributor of GHG emissions after the Electricity sector. GHG emissions from transportation have risen about $16 \%$ since 1990. Road transport contributes about one-fifth of the EU's total emissions. Transport is the only sector in the EU where GHG emissions are still rising.

The growth of emissions (especially $\mathrm{CO}_{2}$ ) depends on the population, which will increase from 7 to 9 billion over the next 40 years. More plurality of the population means more cars, higher demand and therefore, more trucks on the roads. The latest estimates suggest that in 2100 , the level of $\mathrm{CO}_{2}$ emissions will reach a triple amount of emissions in 2000. The relationship between population and emissions is shown in Figure 6.

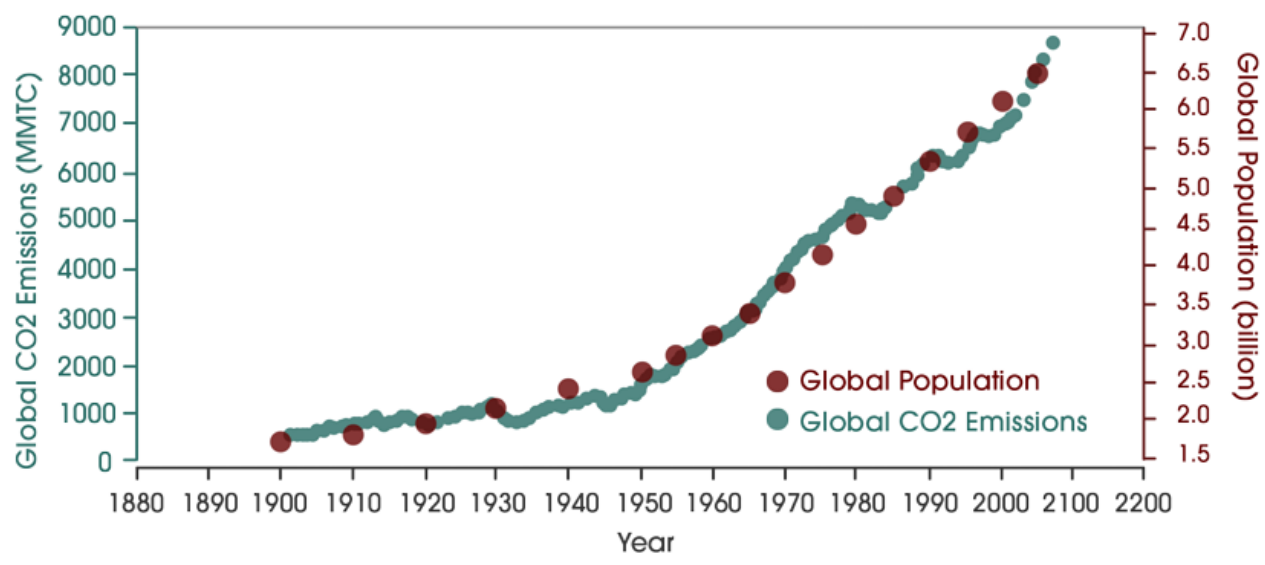

Fig. 6. Relationship between population and $\mathrm{CO}_{2}$ emissions (World Climate Report, 2008).

Research shows that the share of road transport is an incredible $72 \%$ of the total volume of emissions produced from transport (in 2012 in the countries of European Union). In contrast, water and rail transport with their shares of emissions produced as $1 \%$ and $10 \%$ respectively, are the most environmentally-friendly transport departments. Based on this research, we suggested that a part of the transportation performance should be directed to these modes. This solution would not only reduce harmful GHG and $\mathrm{CO}_{2}$ emissions, but it would also reduce external costs arising from road as noise, vibrations, congestions and accidents.

In the terms of infrastructure, railways are the largest competitor of roads. But for the shift of transport performance from road to water transport, there is a need for financing infrastructure of waterways. The European Commission realises the issue of improving the navigability of rivers in the White Book and in the project of TEN-T. 


\section{Conclusion}

Modal split in the European countries is not proportionate, and there is an obvious contrast in inland freight transport. Geographic positions of countries are responsible for the differences - islands or peninsulas have bigger share of road transport. Road transport remains the most widely used mode of transport, whose largest competitor is rail transport.Inland navigation is slightly less transport branch, but it is important in some specific areas, such as corridors of the Rhine river in the Netherlands and countries with connection to the Danube river. These countries have bigger shares of inland navigation.

Increase of traffic in recent years has caused an increase in negative impacts on the environment. Road transportation as one of the most polluting mode of transport is responsible for the growth of external costs, such as congestions, accidents, noise and pollution, especially caused by $\mathrm{CO}_{2}$ and $\mathrm{GHG}$ emissions.

The primary issue of transport is that it causes external costs to the society, such as congestions, pollution, and noise, which are not a part of the transport costs (costs that are paid by final consumer). Fiscal tools can be used to reintegrate these secondary costs in the final price. So, if these secondary (external) costs would be integrated in each mode, prices could balance modal competition for the benefit of the least costly modes.

To reduce the levels of emissions in the future, a larger volume of freight transported by road should be moved to water and rail transport. This will ensure a reduction of greenhouse gas emissions and facilitate highways.

\section{Acknowledgements}

This paper was supported by VEGA as a grant No.1/0331/14: Modelling of Distribution Logistics System with Using Software Solutions. Faculty of Operation and Economics of Transport and Communications, University of Žilina.

\section{References}

Brogan, J.J., Aeppli, A.E., Beagan, D.F. \& Brown A. et al. (2013). Freight Transportation Modal Shares: Scenarios for a Low-Carbon Future. Transportation Energy Futures Series. Cambridge, Department of Energy, Washington, DC.

EU transport in figures - statistical pocketbook 2014, available at: http://ec.europa.eu/transport/facts-fundings/ statistics/doc/2014/pocketbook2014.pdf (3.1.2016)

Fuchs, G. (2010). Model split in European freight transport. Lund: Lund University - School of Economics and Management.

McKinnon, A. (2007). CO 2 Emissions from Freight Transport. An Analysis of UK Data. Edinburgh: Logistics Research Centre, Heriot-Watt University. http://www.greenlogistics.org/SiteResources/d82cc048-4b92-4c2aa014-afleea7d76d0_CO2\%20Emissions\%20from\%20Freight\%20Transport\%20-\%20An\%20Analysis\%20 of\%20UK\%20Data.pdf (28.12.2015)

Reis, S. et al. (2013). Integrating health and environmental impact analysis. Public Health available at: http://www. sciencedirect.com/science/article/pii/S0033350613002424 (15.1.2016)

Rodrigue, J.P. (2013). The geography of transport systems. New York: Routledge.

US Bureau of Transport Statistics, Economic Impact of Shipment Choices, available at: http://www.rita.dot.gov/bts/ programs/freight_transportation/html/shipment_choices.html (15.1.2016)

Worlds climate report: What the Future Holds in Store, 2008, available at: http://www.worldclimatereport.com/ index.php/2008/01/30/what-the-future-holds-in-store/ (18.1.2016) 